IMECE2006-13212

\title{
ENGINEERING ANALYSES FOR RAILROAD TANK CAR HEAD PUNCTURE RESISTANCE
}

\author{
D.Y. Jeong \\ U.S. Department of Transportation \\ Volpe National Transportation Systems Center \\ Cambridge, Massachusetts, USA \\ jeong@volpe.dot.gov \\ H. Yu \\ Chenga Advanced Solutions \& Engineering, LLC \\ Cambridge, Massachusetts, USA \\ yu@volpe.dot.gov
}

\author{
Y.H. Tang \\ U.S. Department of Transportation \\ Volpe National Transportation Systems Center \\ Cambridge, Massachusetts, USA \\ tangy@volpe.dot.gov \\ A.B. Perlman \\ Tufts University \\ Medford, Massachusetts, USA \\ bperlman@tufts.edu
}

\begin{abstract}
This paper describes engineering analyses to estimate the forces, deformations, and puncture resistance of railroad tank cars. Different approaches to examine puncture of the tank car head are described. One approach is semi-empirical equations to estimate the velocity at which puncture is expected to occur. Other approaches apply elastic-plastic finite element analysis. The results from these approaches are compared with experimental data from impact tests, and are shown to provide reasonable estimates of impact forces.
\end{abstract}

\section{INTRODUCTION}

Studies on tank car head puncture were conducted by the Railway Progress Institute - Association of American Railroads (RPI-AAR) ${ }^{1}$ Tank Car Safety Research and Test Project in the 1970s [1]. However, recent train derailments involving the subsequent release of hazardous material have prompted a renewed focus on the structural integrity of tank cars involved in accidents $[2,3,4]$.

This paper describes engineering analyses to estimate the impact forces, deformations, and puncture resistance of railroad tank cars. In the present context, puncture resistance is defined in terms of the impact velocity at which puncture of the tank is expected to occur. These analyses include: (1) semi-empirical (or semi-analytical) equations, (2) static finite element analysis coupled with dynamic lumped mass modeling, and (3) dynamic finite element analysis. Some of the work presented in this paper was documented in previous government reports prepared for the Federal Railroad Administration (FRA) by the Volpe National Transportation Systems Center (Volpe Center) $[5,6]$, but has not been presented in any previous technical papers.

\section{SEMI-EMPIRICAL APPROACH}

Semi-empirical equations to calculate puncture velocity were originally developed by the RPI-AAR Tank Car Safety Research and Test Project for bare tank heads [7], and later modified by the DuPont Company to account for shield protection and thermal insulation.

In deriving these equations, the energy transmitted by wave propagation is considered small compared to the initial kinetic energy and the energy dissipated during deformation, and is therefore neglected. In such cases, local indentations or penetrations are strongly coupled to the overall deformation of the structure. Moreover, the process is considered as isothermal so that temperature and other thermodynamic effects are also neglected.

The maximum force due to a coupler impacting the head of a tank is related to the indentation or dent depth by:

$$
F(d)=35 \times 10^{6} d^{3 / 2}\left(\frac{h}{2 a}\right)^{3}\left(\frac{p+15}{15}\right)^{0.6}
$$

\footnotetext{
${ }^{1}$ In 2003, the Railway Progress Institute (RPI) consolidated with the Railway Supply Association to form the Railway Supply Institute (RSI).
}

This material is declared a work of the U.S. Government and is not subject to copyright protection in the United States. Approved for public release; distribution is unlimited. 
where $F$ is the maximum impact force (in units of kips), $d$ is the dent depth (in inches), $h$ is the shell thickness (in inch), $a$ is the tank head radius (in inches), and $p$ is the internal pressure (in psi). The exponent of $3 / 2$ for $d$ indicates that a Hertzian relationship between the contact force and the indentation was assumed in the formulation. Moreover, the Hertz contact assumption implies that the problems of elastic contact and elastic impact are treated identically in this formulation. The assumption of Hertz contact may be valid for low-velocity impacts, but may be questionable for impacts involving large plastic deformations or those resulting in puncture or other types of failure.

The semi-empirical equation for indentation or dent depth is a linear function of impact velocity:

$$
d(v)=8.8 \times 10^{-5}\left(\frac{2 a}{h}\right)^{2} \alpha^{1 / 16}\left(\frac{W_{1} v}{g}\right)\left[1-0.23\left(\frac{p}{40}\right)^{0.5}\right]
$$

where $d$ is the indentation relative to its undeformed condition (in inches), $v$ is the impact velocity (in miles per hour, mph), $W_{1}$ is the weight of the impacting car (in kips), and $g$ is the acceleration due to gravity $\left(386 \mathrm{in} / \mathrm{s}^{2}\right)$. Also, $\alpha$ is the ratio between the weights of the tank car and the impacting car or $W_{2} / W_{1}$.

An equation to calculate the maximum coupler force as a function of impact velocity can be derived by combining equations (1) and (2):

$$
F(v)=0.00383 \alpha^{3 / 32}\left(W_{1} v\right)^{3 / 2} \lambda(p)
$$

In this equation, a dimensionless function of internal pressure is defined as

$$
\lambda(p)=\left[1-0.23\left(\frac{p}{40}\right)^{0.5}\right]^{3 / 2}\left(\frac{p+15}{15}\right)^{0.6}
$$

The numerical value of $\lambda$ is always greater than or equal to 1 . For example, $\lambda$ equals 1.0 when the internal pressure is zero; $\lambda$ is equal to 1.72 when the internal pressure is $100 \mathrm{psi}$.

Failure is assumed to occur when the maximum stress is greater than or is equal to the ultimate shear strength. Moreover, the failure criterion is based on the transverse shear component of stress, which is calculated for a flat circular plate with clamped edges subjected to a concentrated load offset from the center to represent a "knuckle" impact. An analytical solution for transverse shear is calculated from the first five terms of an infinite series solution [9]. Mathematically, the failure criterion is expressed as:

$$
1.81 \frac{F}{a h} \geq \tau_{u}
$$

where $\tau_{u}$ is the ultimate shear strength of the head material (in ksi). In general, mechanical properties for a given material are reported in terms of yield strength, ultimate tensile strength, and percent elongation. Assuming that triaxial stresses are related to uniaxial properties by the von Mises equivalent stress, the ultimate shear strength is equal to $57.7 \%$ of the ultimate tensile strength.

Figure 1 compares impact forces measured in the RPIAAR tank car head study [1] with those calculated from equation (3). The data are segregated by the internal pressure level in the tank. The straight line shown in the plot represents perfect correlation. Data points to the right of the straight line represent cases where the calculated impact forces overestimated the measured test results. A quantitative measure of the overall scatter observed in the plot is estimated by calculating the correlation coefficient, which is equal to 0.920 . The correlation coefficient for a perfect correlation is equal to one. The correlation coefficient corresponding to the data for only non-pressurized tank cars is equal to 0.988 , and for only pressurized cars the correlation coefficient is 0.773 . These values for the correlation coefficient indicate that the semiempirical equation for impact force is more accurate for nonpressurized tanks than it is for pressurized tanks.

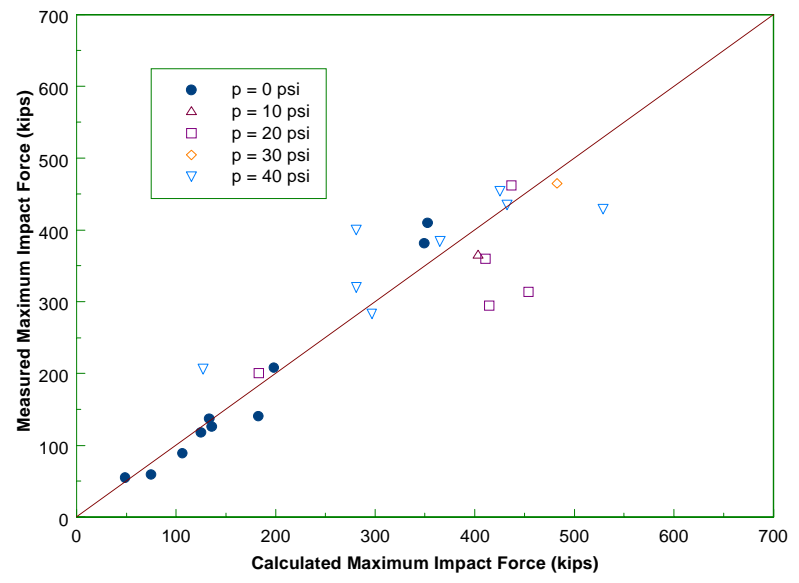

Fig. 1: Comparison between calculated and measured impact forces.

Figure 2 compares measured indentation or dent depth from the RPI-AAR tests [1] with those calculated with equation (2). Similarly, this plot segregates the data into non-pressurized tank cars and pressurized tank cars. The correlation coefficient for all data is 0.777 . If only non-pressurized tank cars are considered, the correlation coefficient is 0.809 ; if only pressurized tank cars are considered, it is 0.757 . As in the case

This material is declared a work of the U.S. Government and is not subject to copyright protection in the United States. Approved for public release; distribution is unlimited. 
of calculating impact forces, the semi-empirical equation for dent depth is relatively more accurate for non-pressurized tank cars than for pressurized tank cars.

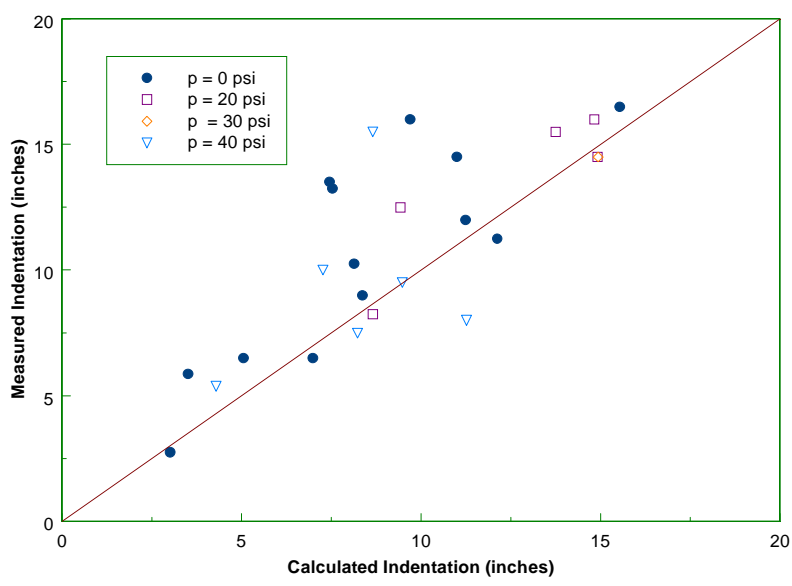

Fig. 2: Comparison between calculated and measured indentations.

An expression to calculate puncture velocity (i.e., the velocity at which puncture of the tank may be expected to occur) can be derived by substituting the equation for maximum coupler force into the failure criterion:

$$
v_{p}=\frac{27.6}{W_{1} \alpha^{1 / 16}}\left[\frac{\tau_{u} a h}{\lambda(p)}\right]^{2 / 3}
$$

In this equation, $v_{p}$ is the puncture velocity in miles per hour (mph).

Test results indicate that there is a small reduction in impact velocity between head shield and tank car head impacts, suggesting that the head shield has a negligible energy absorption capability. Apparently, the primary benefit of a head shield is to increase the overall material thickness. In calculating the puncture velocity, the apparent increase in material thickness is represented by an effective thickness parameter defined as

$$
h_{\text {eff }}=\left[h_{h}^{1.33}+h_{s}^{1.33}+h_{j}^{1.33}\right]^{1 / 1.33}
$$

where $h_{h}$ is the tank car head thickness, $h_{s}$ is the head shield thickness, and $h_{j}$ is the jacket thickness. The exponent of 1.33 is an empirical constant.

A small but measurable reduction in impact velocity has been observed when a coupler hits a head shield and then when it hits the tank car head because, in general, the head shield is placed with a gap distance between it and the tank head.
Applying the principle of energy conservation, a so-called gap factor can be derived:

$$
K_{G}=\frac{1}{\sqrt{1-\frac{2 F\left(v_{p b}\right) \Delta g}{\left(17.6 v_{p b}\right)^{2} W_{1}}}}
$$

where $\Delta$ is the gap distance between the head shield and the tank head, $v_{p b}$ is the puncture velocity for a bare tank car head (in mph) with effective thickness as defined in equation (7), or

$$
v_{p b}=\frac{27.6}{W_{1} \alpha^{1 / 16}}\left[\frac{\tau_{u} a h_{e f f}}{\lambda(p)}\right]^{2 / 3}
$$

Then, the puncture velocity for a tank car head with shield protection and/or an insulating jacket can be calculated from:

$$
v_{p}=K_{G} \cdot v_{p b}
$$

where $K_{G}$ is the gap factor defined by equation (8) and $v_{p b}$ is defined by equation (9).

A secondary benefit of the head shield is that it prevents puncture by blunting the corner edges of the coupler making puncture less likely. This effect has not been taken into account explicitly in these equations.

The semi-empirical equations for puncture velocity were evaluated by comparing results from these equations with test data from various sources. The first source is the RPI-AAR Tank Car Head Study [1] which included 42 full-scale tests (34 on bare head tank cars, 6 with a head shield, and 2 with an insulating jacket) and 3 tests on DOT112A340W tank cars (2 on bare heads and 1 with a head shield). The second source is 9 full-scale impact tests conducted on chlorine tank cars (3 with head protection and 6 with steel jackets) [9]. The third source of test data is 6 impact experiments that were conducted on aluminum DOT111A60ALW1 tank cars (3 with a bare head and 3 with a head shield) [10].

Table 1 summarizes the comparison between the calculated puncture velocity and the results from the various impact tests. The data from the three different sources represent a total of 65 test cases. The semi-empirical equation for puncture velocity agreed with the test result in 51 out of these 65 cases. Of the 14 cases where the predicted and actual outcomes disagreed, the semi-empirical equation overestimated the puncture velocity in 6 cases. In other words, the semi-empirical equation predicted that no puncture would occur in 6 cases where puncture occurred in the test. But in 2 of the 6 cases in which the semi-empirical equations overestimated the actual puncture velocity, the difference was less than $1 \mathrm{mph}$.

This material is declared a work of the U.S. Government and is not subject to copyright protection in the United States. Approved for public release; distribution is unlimited. 
Table 1: Comparison of Impact Test Data with SemiEmpirical Equation for Puncture Velocity

\begin{tabular}{|l|c|c|c|}
\hline Source & Cases & Disagree & Over \\
\hline RPI-AAR tests [1] & 45 & 10 & 4 \\
\hline $\begin{array}{l}\text { FRA tests on chlorine } \\
\text { tank cars [9] }\end{array}$ & 14 & 3 & 1 \\
\hline $\begin{array}{l}\text { FRA tests on } \\
\text { aluminum tank cars } \\
\text { [10] }\end{array}$ & 6 & 1 & 1 \\
\hline TOTALS & 65 & 14 & 6 \\
\hline
\end{tabular}

\section{ENGINEERING APPROACH}

Alternative methods to examine the impact forces and deformations of tank car heads involve elastic-plastic finite element (FE) analysis.

The physics of impact may be captured with a dynamic, elastic-plastic FE model. But the development of a model that includes impact dynamics as well as nonlinear material behavior may be labor intensive, and the model execution may require high computational times. Moreover, the combination of finite difference in time for dynamics and nonlinear material behavior makes it difficult in practice to obtain good model performance without assuming extremely small time steps.

In linear problems, numerical stabilities in $\mathrm{FE}$ analysis are self-evident because the solution grows without limit. In nonlinear problems, with elastic-plastic or other energydissipating materials, extra energy introduced into the system by numerical instabilities may be dissipated by plastic work which makes it possible for the instability to be arrested. An arrested instability may be difficult to detect because the solution, which may be in error by $10 \%$ to $100 \%$ or more, may appear to be reasonable [11].

For these reasons, an engineering method was developed which couples static elastic-plastic finite element analysis with a dynamic lumped-mass model, which is shown schematically in Figure 3. The spring characteristic representing the stiffness of the tank car head as it deforms is assumed to be a nonlinear function of impact load. The impact load-deformation behavior is calculated from static elastic-plastic finite element analysis. The lumped-mass model uses the non-linear load-deflection curve as calculated from the static FE analysis to calculate the impact force as a function of closing velocity. Moreover, the lumped-mass model provides a means to verify the results from a dynamic finite element model.

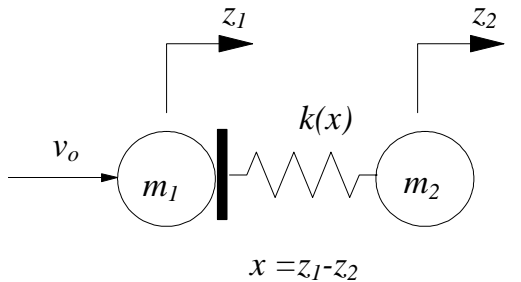

Fig. 3: Dynamic lumped-mass model for tank car impacts.

For mathematical convenience, the nonlinear spring characteristic in the dynamic lumped-mass model may be defined by a piecewise linear curve. The piecewise linear representation allows for an analytical solution to the equations of motion to the lumped-mass system [12]. The analytical equations for this particular application were derived and described in previous work [6]. Alternatively, the equations of motion may be solved numerically.

The finite element analyses described in this paper were carried out using the commercial codes LS-DYNA [13] and ABAQUS [14]. Elastic-plastic (E-P) material behavior is modeled using the Ramberg-Osgood equation for strain as a function of stress:

$$
\varepsilon=\frac{\sigma}{E}+\left(\frac{\sigma}{K}\right)^{n}
$$

where $\varepsilon$ is the strain, $\sigma$ is the stress, and $E$ is the modulus of elasticity (30,000 ksi assumed for tank car steel). Also, $n$ and $K$ are material constants. Table 2 lists the assumed values of these constants for two different tank car steels. The current tank car fleet has been built predominantly using TC-128B. The cars used in impact tests conducted in the 1970s [1] were made from AAR M-115. The table also lists the yield and ultimate tensile strengths assumed for these tank car steels.

Table 2: Assumed Ramberg-Osgood (R-O) Material Constants and Mechanical Properties for Two Tank Car Steels

\begin{tabular}{|l|c|c|}
\hline & AAR M-115 & TC-128B \\
\hline Hardening exponent, $n$ & 6.65 & 9.41 \\
\hline R-O Constant, $K$ & $73.1 \mathrm{ksi}$ & 96.8 \\
\hline Yield strength & $30 \mathrm{ksi}$ & $50 \mathrm{ksi}$ \\
\hline Tensile strength & $60 \mathrm{ksi}$ & $81 \mathrm{ksi}$ \\
\hline
\end{tabular}

This material is declared a work of the U.S. Government and is not subject to copyright protection in the United States. Approved for public release; distribution is unlimited. 
Figures 4 and 5 show the finite element (FE) meshes used to represent the ellipsoidal tank car head. The quartersymmetric mesh is used for cases where the load is applied at the center of the head. The half-symmetric mesh is used for cases with off-center loading. Moreover, three-dimensional solid elements are used to construct these meshes. Two layers of solid elements are used to model the thickness of the tank car head.

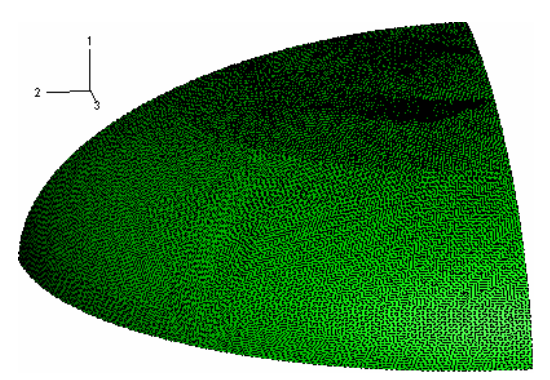

Fig 4: Quarter-symmetric mesh for typical tank car head.

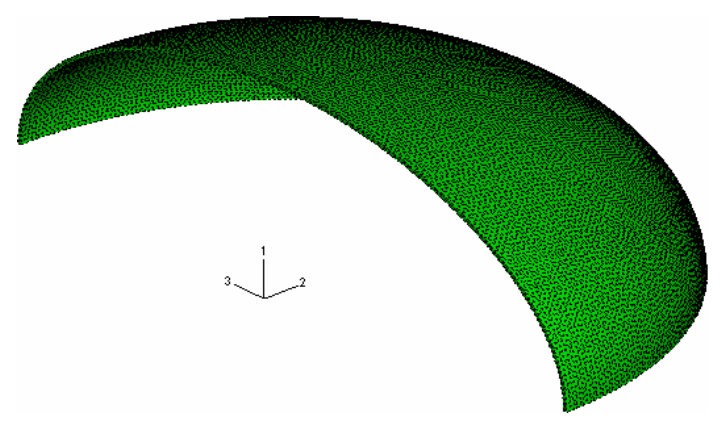

Fig 5: Half-symmetric mesh for typical tank car head.

In order to ascertain confidence in the model development, results from the elastic-plastic (EP) finite element (FE) model are compared with a closed-form solution for the plastic collapse of a rigid-plastic ellipsoidal shell subjected to a concentrated load applied at the center [15]. Figure 6 compares the closed-form (analytical) solution with finite element results using ABAQUS for AAR M-115 tank car steel. In these results, the ellipsoidal tank head has an aspect ratio of 2 to 1 , diameter of 87.5 inches, thickness of 0.5 inches, and no internal pressure. In the FE model, the applied load is distributed over a 1 square-foot area at the center of the cap. In addition, FE results are shown for two material models regarding stressstrain behavior: elastic-perfectly plastic (EPP) and elasticplastic behavior modeled with the Ramberg-Osgood equation. In the analytical solution, the flow stress was assumed to be equal to the yield strength of the material. The solution algorithm in the finite element analysis uses Riks method [16], which is efficient when the static load-deflection curve is expected to exhibit snap-through or snap-back behavior.

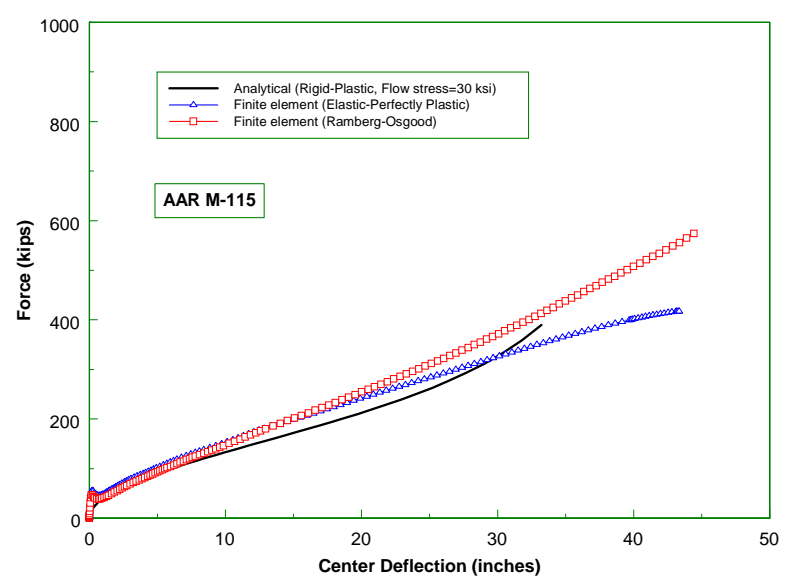

Fig. 6: Analytical and FE results for an ellipsoidal cap loaded at the center (AAR M-115 tank car steel).

Figure 7 shows similar results for TC-128B tank car steel. Given the differences in the assumed material behavior and applied loading, these comparisons show reasonable agreement.

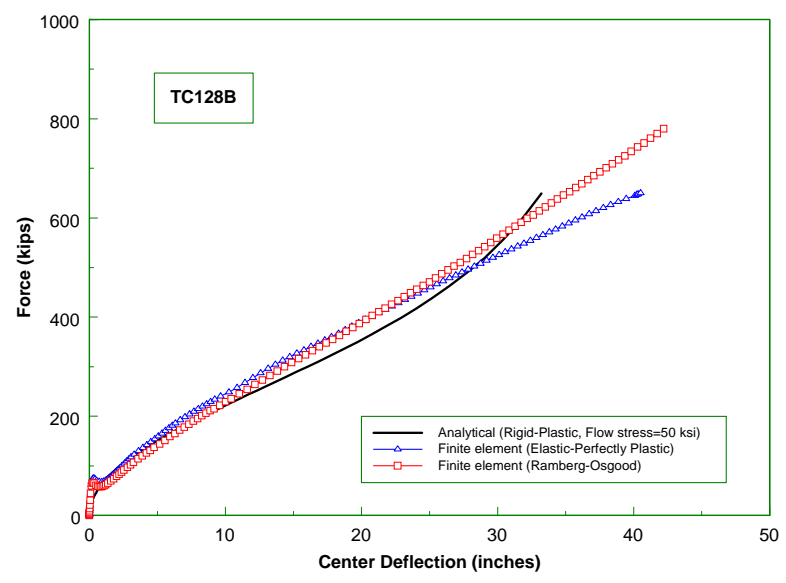

Fig. 7: Analytical and FE results for an ellipsoidal cap loaded at the center (TC-128B tank car steel).

Figure 8 shows the effect of load location on the static elastic-plastic (i.e., Ramberg-Osgood) finite element results for an ellipsoidal end cap assuming AAR M-115 tank car steel. In the off-center case, the load is applied at a distance equal to one-third of the radius down from center. The figure shows a slight stiffening effect for the off-center loading case.

This material is declared a work of the U.S. Government and is not subject to copyright protection in the United States. Approved for public release; distribution is unlimited. 


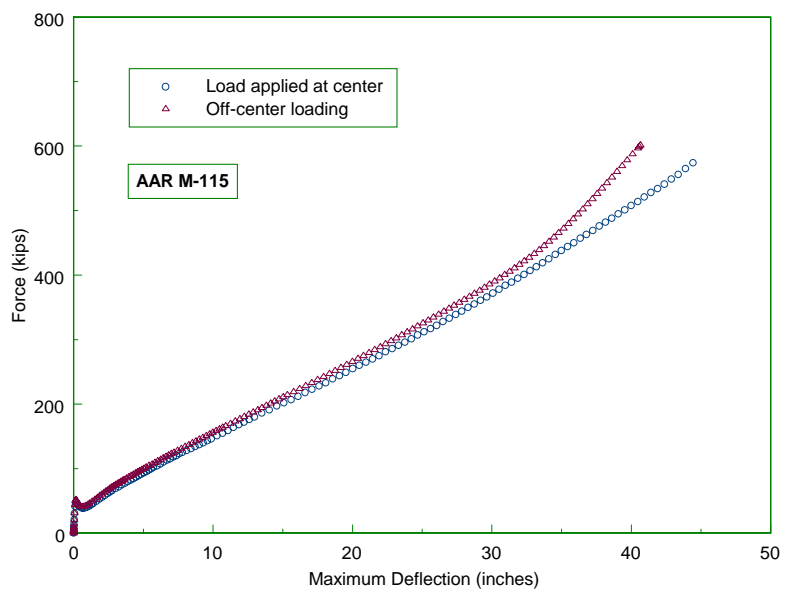

Fig. 8: Effect of load location on static elastic-plastic analysis (AAR M-115 tank car steel).

The load-deflection results from the static elastic-plastic finite element analysis for off-center loading are then used as input to the lumped-mass model to calculate impact force as a function of approach velocity or closing speed. Figure 9 shows the results from three different approaches: (1) the semiempirical method, (2) the lumped-mass model, and (3) dynamic elastic-plastic finite element analysis. In these results, a ram car that weighs 128.9 kips is assumed to strike an empty tank car weighing 48.5 kips. The semi-empirical method calculates impact forces that are lower than the lumped-mass model and dynamic FE analysis for relatively low closing speeds (roughly less than $15 \mathrm{mph}$ ). Conversely at relatively high closing speeds, the semi-empirical method calculates impact forces greater than the lumped-mass and the dynamic FE analyses.

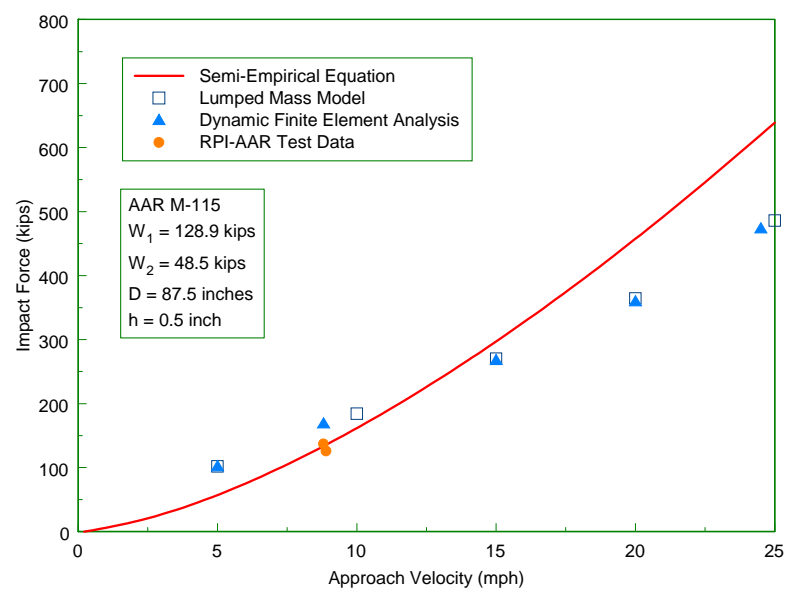

Fig. 9: Impact force as a function of approach velocity.

\section{CONCLUDING REMARKS}

The semi-empirical or semi-analytical approach to calculate impact forces, indentations, and puncture velocity provides reasonable agreement with experimental data from three different sources. The agreement between predictions from this approach and experimental data becomes worse when head shield protection or an insulating jacket is present and when the tank is internally pressurized.

Alternative engineering approaches to examine puncture resistance were described which apply nonlinear finite element analysis which minimizes the need for empiricism. The results from this work indicate that the semi-empirical method and the engineering approaches provide similar results for impact forces.

Research is ongoing to apply various fracture initiation criteria to the dynamic finite element analyses to estimate the force and corresponding velocity at which puncture is expected to occur. Work is also ongoing to examine the effect of fluidstructure interaction on the dynamic response of tank car head impacts.

\section{ACKNOWLEDGMENTS}

The work described in this paper was sponsored by the Federal Railroad Administration, Office of Research \& Development. Ms. Claire Orth is the Chief of the Equipment and Operating Practices Division. Mr. Francisco Gonzalez is the project manager for research on railroad tank cars.

Technical discussions with Dr. Oscar Orringer and Mr. Frank DiMasi of the Volpe Center have contributed to this research and are acknowledged.

\section{REFERENCES}

[1] Phillips, E.A., Olsen, L., 1972: "Final Phase 05 Report on Tank Car Head Study,” RPI-AAR Tank Car Safety Research and Test Project, RA-05-17.

[2] National Transportation Safety Board, "Derailment of Canadian Pacific Railway Freight Train 292-16 and Subsequent Release of Anhydrous Ammonia Near Minot, North Dakota January 18, 2002,” Railroad Accident Report NTSB/RAR-04/01, March 2004.

[3] National Transportation Safety Board, "Collision of Norfolk Southern Freight Train 192 With Standing Norfolk Southern Local Train P22 With Subsequent Hazardous Materials Release at Graniteville, South Carolina January 6, 2005,” Railroad Accident Report NTSB/RAR-05/04, November 2005.

[4] National Transportation Safety Board, "Collision of Union Pacific Railroad Train MHOTU-23 With BNSF Railway Company Train MEAP-TUL-126-D With Subsequent Derailment and Hazardous Materials Release, Macdona,

This material is declared a work of the U.S. Government and is not subject to copyright protection in the United States. Approved for public release; distribution is unlimited. 
Texas, June 28, 2004" Railroad Accident Report NTSB/RAR-06/03, July 2006.

[5] Jeong, D.Y., Tang, Y.H., Perlman, A.B., 2001: "Evaluation of Semi-Empirical Analyses for Railroad Tank Car Puncture Velocity, Part I: Correlations with Experimental Data,” Final Report, DOT/FRA/ORD-01/21.I.

[6] Jeong, D.Y., Tang, Y.H., Perlman, A.B., 2001: "Evaluation of Semi-Empirical Analyses for Railroad Tank Car Puncture Velocity, Part II: Correlations with Engineering Analyses,” Final Report, DOT/FRA/ORD-01/21.II.

[7] Shang, J.C., Everett, J.E., 1972: "Impact Vulnerability of Tank Car Heads," Shock and Vibration Bulletin 42, 197210.

[8] Timoshenko, S., Woinowsky-Krieger, S., 1959: Theory of Plates and Shells, $2^{\text {nd }}$ Edition, New York: McGraw-Hill Book Company.

[9] Coltman, M., Hazel, M., 1992: "Chlorine Tank Car Puncture Resistance Evaluation,” Final Report, DOT/FRA/ORD-92/11.

[10]Larson, W.G., 1992: “Aluminum/Cold Temperature Tank Car Puncture Resistance Tests: Data Report,” Final Report, DOT/FRA/ORD-92/29.

[11] Cook, R.D., Malkus, D.S., Plesha, M.E., 1989: Concepts and Applications of Finite Element Analysis, $3^{\text {rd }}$ Edition, New York: John Wiley\& Sons.

[12] Timoshenko, S., Young, D.H., Weaver, W., 1974: Vibration Problems in Engineering, $4^{\text {th }}$ Edition, New York: McGrawHill Book Company.

[13]LS-DYNA3D User's Manual, Version 940, Livermore Software Technology Company, Livermore, California.

[14]ABAQUS User's Manual, Hibbit, Karlsson \& Sorensen Inc., Pawtucket, Rhode Island.

[15] de Oliveria, J.G., Weirzbicki, T., 1982: "Crushing Analysis of Rotationally Symmetric Plastic Shells," Journal of Strain Analysis for Engineering Design 17, 229-23.

[16]Riks, E., 1979: "An incremental approach to the solution of snapping and buckling problems," International Journal of Solids and Structures 15, 524-551.

This material is declared a work of the U.S. Government and is not subject to copyright protection in the United States. Approved for public release; distribution is unlimited. 